\title{
Cheiro-Oral Syndrome in a Patient from a Cortical Infarction in the Midfrontal Gyrus
}

\author{
Jae Young An In Uk Song Sung Hun Kim Yeong In Kim Kwang Soo Lee \\ Joong Seok Kim
}

Department of Neurology, College of Medicine, The Catholic University of Korea, Seoul, Korea

\begin{abstract}
Dear Sir,
Cheiro-oral syndrome (COS) is a wellknown sensory disturbance which affects the unilateral hand and mouth regions. Since Sitting's initial report [1], an increasing number of cases of COS have been reported [2]. In most cases of cortical COS the lesion was extended to the postcentral gyrus as a primary sensory cortex, but the lesion of the precentral gyrus causing COS was described in previous reports [3-5]. We describe a case with COS due to a frontal infarction and discuss the pathogenesis of frontal COS.
\end{abstract}

\section{Case Report}

A 67-year-old hypertensive man suddenly developed paresthesia in the left thumb and drooling from the left side of his mouth. The patient was unaware of saliva around the chin until his wife mentioned it. Other neurological symptoms, except sensory symptoms, were not noted. Unawareness of drooling resolved in a few minutes. Three hours later, he visited ER with moderate improvement of sensory symptoms in the thumb. The patient had no personal history of any other neurological disorders. Neurological examination revealed a mild sensory defect for pinprick and temperature modalities restricted to the thumb and minimal left central facial weakness. Lemniscal sensory modalities were normal. The rest of the neurological examination was normal. Routine blood was normal except for hyperlipidemia and hyperglycemia. A brain MRI performed several hours later revealed an acute small ischemic lesion at the right midfrontal gyrus and chronic ischemic lesion at the right parietal lobe on diffusion-weighted images and $\mathrm{T}_{2}$-weighted images (fig. 1). Carotid and vertebral arteries were normal at $M R$ angiography. 24-hour Holter monitoring showed rare atrial and ventricular premature complexes and M-mode and twodimensional echocardiographies showed ischemic cardiomyopathy with mild systolic dysfunction and moderate aortic re- gurgitation. Several days later, sensory symptoms in the thumb had completely resolved.

\section{Discussion}

Our patient complained of transient unawareness of drooling of saliva, which may be due to a sensory change of the perioral area and paresthesia in the thumb after cortical infarction. Because minimal facial weakness had not changed over a follow-up period lasting several months,
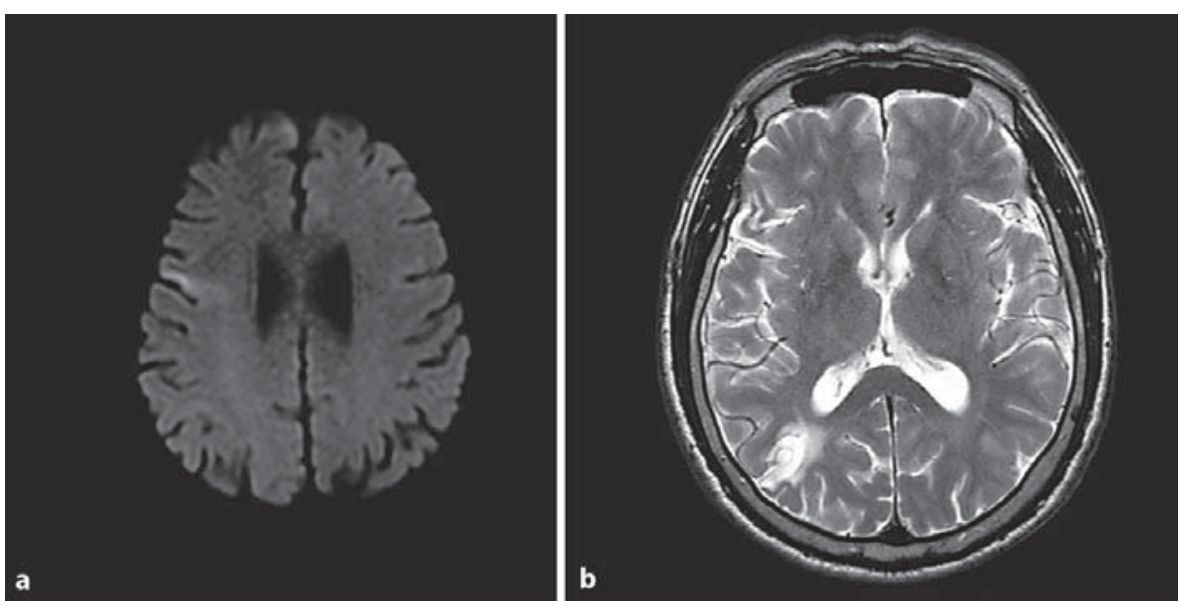

Fig. 1. a Diffusion-weighted MRI showed the acute small infarction in the right midfrontal gyrus. $\mathbf{b} \mathrm{T}_{2}$-weighted image showed chronic ischemic parietal infarction.

\section{KARGER}

Fax +41613061234

E-Mail karger@karger.ch

www.karger.com (c) 2008 S. Karger AG, Basel $0014-3022 / 08 / 0594-0219 \$ 24.50 / 0$

Accessible online at: www.karger.com/ene
Joong-Seok Kim

Department of Neurology, Kangnam St. Mary's Hospital

505, Banpo-dong, Seocho-gu, Seoul 137-701 (Korea)

Tel. +82 2590 2091, Fax +82 25999686

E-Mail neuronet@catholic.ac.kr 
we thought that the minimal left facial weakness was a neurological sequela of a previous silent infarction and this patient had COS.

The exact mechanism of acute cortical infarction in our patient was uncertain but may be caused by brain embolism due to relatively intact cerebral vessels, ischemic cardiomyopathy and a previous silent cortical infarction.

Many cases of COS due to various lesions such as corona radiata, thalamus, internal capsule, midbrain, and pons, either unilateral or bilaterally, have been reported [2]. The close proximity of the ascending sensory tracts carrying fibers from the perioral and cheiral topography has been proposed as the cause of COS [6]. Although the representation areas of the perioral and cheiral dermatomes are separate from each other in the sensory cortex [6], there are reports describing cortical COS of variable etiology, such as subdural hematoma, cortical infarct, meningioma and arteriovenous malformation [7]. Several mechanisms of cortical COS have been proposed, including epileptogenesis, a precondition of neuronal vulnerability, mechanical compression or vascular compromise [2, 7-9]. However, the exact pathogenesis of cortical COS remains unclear.

Though the precentral gyrus is normally associated with movement and the postcentral gyrus with sensory function [6], movement is also accompanied by activation of the postcentral gyrus and somatosensory stimuli also activated the precentral gyrus [10]. Motor and sensory hand cortices overlap and are not divided in a simple manner by the central sulcus. Cortical mapping studied by electrical stimulation through a subdural grid electrode showed distribution of hand sensory responses extending $6.8 \mathrm{~cm}$ anterior and $2.2 \mathrm{~cm}$ posterior to the central sulcus [11]. The lesion located at a considerable distance from the central sulcus may cause sensory change in the hand. Furthermore, previous studies using functional imaging have demonstrated a shift in the cortical activation site in association with stroke $[12,13]$. Preexisting vascular compromise leads to the reorganization of the representation areas of the cheiral and perioral topographies, possibly resulting in their enlargement and extension towards each other in close proximity [7]. These changes may contribute to the pathogenesis of cortical COS. Although study of cortical maps was not obtained in our patient, we thought that a previous silent parietal cortical infarction may cause remodeling of sensory representation maps. However, our case shows that COS was caused by cortical lesions situated in various locations, due to widely distributed sensory cortical representation of the hand or post-infarct reorganization of cortical representation areas.

\section{References}

1 Sitting O: Klinische Beiträge zur Lehre von der Lokalisation der sensiblen Rindenzentren. Prager Med Wochenschr 1914;45:548550.

2 Chen WH, Lan MY, Chang YY, Chou MS, Liu JS, Chen SS: Bilateral cheiro-oral syndrome. Clin Neurol Neurosurg 1997;99:239243.

3 Shiga K, Makino M, Ueda Y, Nakajima K, Hirata T: Cheiro-oral syndrome following a cortical brain infarction in the precentral gyrus and at the base of the central sulcus. A case report. Rinsho Shinkeigaku 1996;36: 1104-1106.
4 Oishi N, Udaka F, Kubori T, Nishinaka K, Kameyama M: Cheiro-oral syndrome due to a cortical infarction in the precentral gyrus: A case report. Nō To Shinkei 2003;55:595598.

5 Kim JS: Restricted acral sensory syndrome following minor stroke. Further observation with special reference to differential severity of symptoms among individual digits. Stroke 1994;25:2497-2502.

6 Penfield W, Boldrey E: Somatic motor and sensory representation in the cerebral cortex of man as studied by electrical stimulation. Brain 1937;60:389-443.

7 Chen WH, Lan MY, Chang YY, Lui CC, Chen SS, Liu JS: Cortical cheiro-oral syndrome: a revisit of clinical significance and pathogenesis. Clin Neurol Neurosurg 2006; 108:446-450

8 Bogousslavsky J, Dizerens K, Regli F, Despland PA: Opercular cheiro-oral syndrome. Arch Neurol 1991;48:658-661.

9 Liddel EGT, Phillips CG: Thresholds of cortical representation. Brain 1950;73:125-140.

10 Galea MP, Darian-Smith I: Multiple corticospinal neuron populations in the macaque monkey are specified by their unique cortical origins, spinal termination, and connections. Cereb Cortex 1994;4:166-194.

11 Nii Y, Uematsu S, Lesser MP, Gordon B: Does the central sulcus divide motor and sensory function? Cortical mapping of human hand areas as revealed by electrical stimulation through subdural grid electrode. Neurology 1996;46:360-367.

12 Steven CC, Christopher IM, Seth PF, Bruce RR: A pilot study of somatotopic mapping after cortical infarct. Stroke 2000;31:668671.

13 Weiller C, Ramsay SC, Wise RJS, Frinston KJ, Frackowiak RSJ: Individual patterns of functional reorganization in the human cerebral cortex after capsular infarction. Ann Neurol 1993;33:181-189. 